\title{
Glutathione-Related Antioxidant Defense System in Elderly Patients Treated for Hypertension
}

\author{
J. Rybka $\cdot$ D. Kupczyk $\cdot$ K. Kędziora-Kornatowska • \\ J. Motyl • J. Czuczejko • K. Szewczyk-Golec $\cdot$ M. Kozakiewicz • \\ H. Pawluk • L. A. Carvalho $\cdot$ J. Kędziora
}

Published online: 8 December 2010

(c) The Author(s) 2010. This article is published with open access at Springerlink.com

\begin{abstract}
The purpose of this study was to analyze glutathione antioxidant defense system in elderly patients treated for hypertension. Studies were carried out in the blood collected from 18 hypertensive and 15 age- and sexmatched controls, all subjects age over 60. Hypertensives were on their usual antihypertensive treatment at the time of blood collection. The concentration of glutathione (GSH) in whole blood and activities of glutathione peroxidase (GPx-1), glutathione transferase (GST), and glutathione reductase (GR) in erythrocytes were measured. The data from patients and controls were compared using independent-samples $t$ test. $P$ value of 0.05 and less was considered statistically significant. We observed increased glutathione-related antioxidant defense in treated hypertensive elderly patients (HT) when compared with healthy controls (C). Mean GSH concentration was significantly higher in HT when compared with $\mathrm{C}$ : $3.1 \pm 0.29$ and $2.6 \pm 0.25 \mathrm{mmol} / \mathrm{L}$, respectively, $P<0.001$. Mean activity of GR was significantly higher in HT group if compared with C: $83.4 \pm 15.25 \mathrm{U} / \mathrm{g} \mathrm{Hb}$ versus $64.2 \pm 8.26 \mathrm{U} / \mathrm{g} \mathrm{Hb}$,
\end{abstract}

J. Rybka (凹) · D. Kupczyk · J. Czuczejko ·

K. Szewczyk-Golec · M. Kozakiewicz · H. Pawluk ·

J. Kędziora

Department of Biochemistry, Nicolaus Copernicus University

in Toruń, L. Rydygier Collegium Medicum in Bydgoszcz,

Bydgoszcz, Poland

e-mail: joanna.rybka1@wp.pl

K. Kędziora-Kornatowska · J. Motyl

Department and Clinic of Geriatrics, Nicolaus Copernicus

University in Toruń, L. Rydygier Collegium Medicum

in Bydgoszcz, Bydgoszcz, Poland

L. A. Carvalho

Department of Psychological Medicine, Institute of Psychiatry,

King's College London, London, UK respectively, $P<0.001$. Mean activity of GST was significantly higher in HT group compared with C: $3.0 \pm$ $0.60 \mathrm{mmol} \mathrm{CDNB}-\mathrm{GSH} / \mathrm{mgHb} / \mathrm{min}$ and $2.6 \pm 0.36 \mathrm{mmol}$ CDNB-GSH/mgHb/min, respectively, $P<0.05$. No difference in GPx activity was observed between two groups. These results show that glutathione-related antioxidant defense system was enhanced in elderly hypertensive patients treated for their conditions. This suggests important role of glutathione system in blood pressure regulation. Alterations in concentration and activity of antioxidants observed during antihypertensive medication are likely to be related to the effect of the treatment on NO bioavailability.

Keywords Hypertension - Oxidative stress - Nitrate stress - Glutathione - Glutathione reductase - Glutathione peroxidase $\cdot$ Glutathione transferase

\section{Introduction}

Hypertension is highly prevalent risk factors for cardiovascular disease morbidity and mortality in elderly and can affect as much as $70 \%$ older adults [1]. Although hypertension is a complex trait, which involves multiple and complex pathways, the association with oxidative and nitrosative stress has been shown for hypertension, with the evidence of $\mathrm{NAD}(\mathrm{P}) \mathrm{H}$ oxidase and uncoupled nitric oxide synthase as a major sources of reactive oxygen species (ROS) [2, 3].

Elevated ROS formation in the vascular wall is a key feature of cardiovascular diseases and contributes to endothelial dysfunction and vascular inflammation $[4,5]$. It has been shown that induced hypertension, cardiac hypertrophy, and impaired vascular relaxation are associated with increased superoxide radical. 
The occurrence of oxidative stress may be a consequence of a primary decrease in the antioxidant defense system activity or an elevation of $\operatorname{ROS}$ concentration [6, 7]. Many studies indicate that $\mathrm{O}_{2}^{--}, \mathrm{H}_{2} \mathrm{O}_{2}$, and peroxynitrite $\left(\mathrm{ONOO}^{-}\right)$, which is formed in radical-radical coupling reactions, play an important role in the development of hypertension due to their effect on vascular tone [8]. The relation between increased ROS production and high blood pressure has been explained through enhanced inactivation of the vasodilator nitric oxide (NO) by superoxide radical $\left(\mathrm{O}_{2}^{-}\right)[9,10]$. Vascular NADP $(\mathrm{H})$ oxidases, a major source of vascular ROS production, contribute to regulation of vascular tone [11]. Under physiological conditions, ROS formation by oxidant enzymes and ROS elimination by antioxidant enzymes are balanced in vascular wall.

Although there is evidence for association of blood pressure with oxidative stress, which suggests a possible role of oxidative stress in endothelial dysfunction and pathophysiology of essential hypertension, the relationship between blood pressure and oxidative stress parameters is still not clear [7, 9]. Therefore, more studies aiming to identify free radicals and their intermediates as well as evaluate the traces of radical attack on biological molecules and estimate antioxidant status in hypertension are required. We have hypothesized that cellular glutathione antioxidant defense system is involved in blood pressure regulation.

There are many physiological processes in the human body, which generate reactive oxygen species. ROS are unstable and highly reactive chemical molecules. The univalent reduction of oxygen in mitochondria leads to superoxide radical $\left(\mathrm{O}_{2}^{-}\right)$. Afterward hydrogen peroxide $\left(\mathrm{H}_{2} \mathrm{O}_{2}\right)$ and hydroxyl radical $(\mathrm{OH})$ are produced. Other types of free radicals are nitric oxide radical (NO), peroxynitrite $\left(\mathrm{ONOO}^{-}\right)$, and lipid peroxyl radical (LOO). When production of oxidants overwhelms the cellular antioxidant capacity, the state of oxidative stress occurs, resulting in molecular and cellular tissue damage and severe metabolic malfunctions caused by oxygen radicalmediated toxicity. Specific enzymes and low molecular weight substances eliminate reactive oxygen species and contribute to the redox balance in the cell.

Glutathione serves as a major thiol-disulfide redox buffer for the cell. GSH synthesis is catalyzed by $\gamma$-glutamyl cysteine synthetase ( $\gamma$-GCS) and GSH synthetase. Transcription and activity of $\gamma$-GCS is regulated by many factors and processes such as GSH depletion, GSH conjugation, antioxidants, inflammatory cytokines, nitrosative stress, and oxidative stress [12]. Oxidative stress is associated with GSH oxidation and depletion, which has been observed in hypertensive subjects when compared with non-hypertensive individuals [7, 13, 14]. GSH is utilized as a cofactor by cellular glutathione peroxidase $(\mathrm{Gpx}-1)$ to reduce $\mathrm{H}_{2} \mathrm{O}_{2}$ and organic hydroperoxides. The overall reaction reduces one peroxide molecule to two waters and oxidatively couples two glutathione molecules liberating oxidized glutathione-glutathione disulfide (GSSG) [15]. Glutathione transferase (GST) is a part of a phase 2 detoxification and catalyzes deactivation of many harmful substances and also requires for these reactions reduced glutathione (GSH) as a cofactor [16]. Since many metabolic pathways result in decrease in GSH and an increase in GSSG concentrations, the restoration of reduced glutathione is crucial for the glutathione redox metabolism. Glutathione reductase (GR), catalyzing the reaction $\mathrm{NADPH}+\mathrm{GSSG}+\mathrm{H}(+) \rightarrow \mathrm{NADP}(+)+2 \mathrm{GSH}$, plays an important role in the maintenance of the cell oxidant status [17]. The erythrocyte metabolism of glutathione is essential not only for redox balance but also nitric oxide bioavailability in erythrocytes; hence, it may contribute to the prevalence of hypertension [18].

It has been shown that hypertension is associated with disturbances in glutathione metabolism. Mononuclear cells from hypertensive subjects display significantly lower GSH and higher GSSG values than from the control group [19]. Furthermore, activity of enzymes involved in glutathione metabolism is also disturbed in hypertension since decrease in activities of $\gamma$-GCS, GR, and GPx have been reported $[19,20]$. Decreased activity of antioxidant enzymes in hypertension has been explained by impaired enzyme expression response and enzyme inactivation in the conditions of oxidative stress [19]. It has been also demonstrated that antihypertensive treatment reduces oxidative stress [9, 21] and results in the increase in GSH level and decrease in GSSG and significant enhancement of enzymes involved in glutathione metabolism [19, 22].

Furthermore, it has been also established that aging is associated with disturbances in glutathione metabolism [23, 24]. Different studies have demonstrated both decreased [25] and increased [26] as well as unaltered [27] level of glutathione with age. Regarding GPx activity, results are also contradictory, and we still cannot interchangeably conclude whether the activity of GPx decreases [27] or increases [28] with age. Age-related disturbances in glutathione reductase activity have been also reported [28, 29]. Besides, frequency of homozygotes for glutathione transferase GSTT1 deletion increases with age [30]. Epidemiological studies have shown that advancing age is associated with an increased prevalence of hypertension [31] and genetic effect on blood pressure is modulated by age [32].

Altogether, this evidence suggests that oxidative stress, and in particular, disturbed glutathione metabolism is related to pathogenesis of hypertension. The purpose of this study was to analyze glutathione antioxidant defense system in elderly patients treated for hypertension. The 
concentration of glutathione (GSH) and activities of glutathione peroxidase (GPx-1), glutathione $S$-transferase (GST), and glutathione reductase (GR) were measured.

\section{Methods}

\section{Subjects}

Eighteen elderly hypertensive patients and 15 age- and sexmatched healthy elderly controls were recruited to the Department of Gerontology and Clinic of Geriatrics, Nicolaus Copernicus University Collegium Medicum in Bydgoszcz. All subjects were evaluated by standard physical examination and routine clinical laboratory tests. Table 1 shows the clinical characteristics of the controls and patients.

The hypertension group (HT) consisted of 12 females and 6 males, mean age $82.6 \pm 7.52$. Patients included to this group had been already diagnosed for hypertension and had been treated for their conditions for at least 6 months before they were included in the study. We considered successfully treated hypertensives with blood pressure below 140/90 $\mathrm{mmHg}$ (Table 2). Hypertensives were on their usual antihypertensive medication at the time of blood collection. We decided not to withdraw patients from their usual medication for the ethical reasons, with advanced age being the most important concern and risk factor for possible complications, associated with treatment alterations. Seven hypertensives were treated with combination of statins, $\beta$-blockers, and ACE inhibitors, 5 patients were treated with combinations of statins and $\beta$-blockers, 4 patients were treated with combinations of statins and ACE inhibitors, 1 patient was treated with combination of $\beta$-blocker and ACE-inhibitor, and 1 patient was treated with sartan only.

Exclusion criteria for this group were plasma glucose $\geq 6 \mathrm{mmol} / \mathrm{L}$, cancer, dementia, Alzheimer disease, antioxidants supplementation, smoking, and alcohol abuse.
The control group consisted of 12 females and 3 males, mean age $76.5 \pm 9.56$. Exclusion criteria for this group were hypertension, plasma glucose $\geq 6 \mathrm{mmol} / \mathrm{L}$, cancer, dementia, Alzheimer disease, antioxidants supplementation, smoking, and alcohol abuse.

The study was approved by the Nicolaus Copernicus University in Toruń Human Ethics Committee. Written informed consent was obtained before inclusion in the study.

\section{Blood Samples}

Venous EDTA anticoagulated fasting blood samples were collected in the morning (08:00 am). GSH concentration was determined spectrophotometrically in the whole blood, method described by Beutler. Remaining blood was centrifuged $(2,500 \mathrm{~g}$ for $10 \mathrm{~min})$, and after careful removal of plasma and buffy coat, the red blood cells were washed with cold isotonic saline $(0.89 \% \mathrm{NaCl}, \mathrm{pH}=7.4)$. The hemolysate was prepared by threefold freezing and thawing the washed erythrocytes, suspended in bidistilled water. GPx-1, GST, and GR activities were determined in erythrocytes from hemolyzed blood samples according to Paglia and Valentine [33], Habig [34], and Flohe and Gunzler [35] methods, respectively.

\section{Statistical Analysis}

We have tested the null hypothesis that the mean values of analyzed parameters were not different between hypertensive patients and healthy controls. The values of oxidative stress parameters were expressed as mean \pm S.D. Comparisons were made using independent-samples $t$ test between groups since all variables were continuous and displayed normal distribution. GSH, GPx, GR, and GST association with age, sex, BMI, systolic and diastolic blood pressure, plasma glucose, plasma HDL and LDL cholesterol,

Table 1 Clinical characteristics of the subjects included in the study

\begin{tabular}{lll}
\hline Parameters & Healthy elderly controls & Elderly hypertensive patients \\
\hline Number of subjects & 15 & 18 \\
Age (year) & $76.5 \pm 9.56$ & $82.6 \pm 7.52$ \\
Smoking (yes/no) & $\mathrm{NO}$ & $\mathrm{NO}$ \\
Body mass index $\left(\mathrm{kg} / \mathrm{m}^{2}\right)$ & $26.9 \pm 4.91$ & $28.2 \pm 4.88$ \\
Systolic blood pressure (mmHg) & $130.7 \pm 13.56$ & $129.4 \pm 7.37$ \\
Diastolic blood pressure (mmHg) & $76.9 \pm 10.42$ & $70.6 \pm 11.80$ \\
Plasma glucose (mmol/L) & $5.27 \pm 0.42$ & $5.07 \pm 0.64$ \\
Plasma HDL cholesterol (mmol/L) & $1.2 \pm 0.22$ & $1.2 \pm 0.31$ \\
Plasma LDL cholesterol (mmol/L) & $2.2 \pm 0.88$ & $2.4 \pm 0.40$ \\
Triglycerides (mmol/L) & $1.6 \pm 0.72$ & $1.8 \pm 0.68$ \\
\hline
\end{tabular}

Values are expressed as mean \pm SD. There were no statistically significant differences between groups; $P<0.05$ was considered statistically significant 
Table 2 Parameter values of patients and controls

\begin{tabular}{|c|c|c|c|c|c|c|c|c|c|c|}
\hline Group & Gender & Age & BMI & $\begin{array}{l}\text { Systolic } \\
\text { blood pressure } \\
{[\mathrm{mmHg}]}\end{array}$ & $\begin{array}{l}\text { Diastolic } \\
\text { blood pressure } \\
{[\mathrm{mmHg}]}\end{array}$ & $\begin{array}{l}\text { GSH } \\
{[\mathrm{mmol} / \mathrm{L}]}\end{array}$ & $\begin{array}{l}\text { GPx } \\
{[\mathrm{U} / \mathrm{gHb}]}\end{array}$ & $\begin{array}{l}\text { GR } \\
{[\mathrm{U} / \mathrm{gHb}]}\end{array}$ & $\begin{array}{l}\text { GST [mmol } \\
\text { CDNB-GSH/ } \\
\mathrm{mgHb} / \mathrm{min}]\end{array}$ & $\begin{array}{l}\text { MDA } \\
{[\mathrm{mmol} / \mathrm{gHb}]}\end{array}$ \\
\hline Hypertension & Female & 82 & 33 & 129 & 79 & 2.6 & 10.8 & 110.7 & 2.9 & 0.203 \\
\hline Hypertension & Female & 86 & 24 & 130 & 49 & 3.0 & 13.8 & 101.8 & 3.7 & 0.204 \\
\hline Hypertension & Female & 79 & 25 & 119 & 71 & 3.3 & 16.5 & 71.0 & 4.1 & 0.248 \\
\hline Hypertension & Female & 88 & 32 & 136 & 76 & 2.8 & 14.2 & 96.0 & 2.3 & 0.230 \\
\hline Hypertension & Male & 84 & 27 & 139 & 87 & 3.0 & 12.7 & 83.6 & 2.5 & 0.228 \\
\hline Hypertension & Female & 84 & 26 & 131 & 62 & 3.6 & 12.1 & 99.1 & 2.5 & 0.289 \\
\hline Hypertension & Male & 66 & 31 & 120 & 59 & 3.5 & 13.6 & 82.6 & 2.2 & 0.231 \\
\hline Hypertension & Female & 91 & 24 & 136 & 70 & 3.2 & 13.4 & 71.5 & 2.7 & 0.184 \\
\hline Hypertension & Female & 86 & 33 & 139 & 64 & 3.2 & 14.9 & 105.9 & 2.3 & 0.181 \\
\hline Hypertension & Female & 89 & 28 & 121 & 54 & 2.8 & 17.3 & 82.2 & 2.5 & 0.174 \\
\hline Hypertension & Male & 80 & 15 & 121 & 81 & 3.0 & 14.8 & 82.0 & 3.6 & 0.228 \\
\hline Hypertension & Male & 75 & 26 & 138 & 89 & 3.0 & 12.7 & 73.6 & 2.9 & 0.249 \\
\hline Hypertension & Female & & 35 & 122 & 69 & 3.0 & 11.0 & 87.5 & 3.7 & 0.133 \\
\hline Hypertension & Male & 74 & 34 & 133 & 85 & 3.5 & 10.9 & 71.0 & 3.5 & 0.185 \\
\hline Hypertension & Female & 83 & 32 & 138 & 66 & 3.0 & 14.2 & 68.1 & 3.1 & 0.195 \\
\hline Hypertension & Female & 93 & 29 & 121 & 56 & 2.7 & 11.0 & 57.9 & 3.5 & 0.209 \\
\hline Hypertension & Female & 92 & 25 & 132 & 81 & 3.5 & 12.0 & 93.8 & 3.8 & 0.254 \\
\hline Hypertension & Male & 72 & 29 & 125 & 73 & 3.1 & 10.9 & 63.4 & 3.0 & 0.241 \\
\hline Control & Female & 68 & 27 & 109 & 78 & 2.1 & 16.7 & 64.6 & 2.0 & 0.305 \\
\hline Control & Female & 66 & 23 & 108 & 78 & 2.7 & 12.6 & 84.1 & 2.4 & 0.300 \\
\hline Control & Female & 77 & 28 & 153 & 79 & 2.6 & 16.7 & 64.5 & 2.6 & 0.280 \\
\hline Control & Female & 66 & 27 & 145 & 75 & 2.8 & 14.1 & 74.1 & 2.9 & 0.310 \\
\hline Control & Female & 78 & 15 & 118 & 70 & 2.3 & 17.0 & 53.0 & 3.0 & 0.255 \\
\hline Control & Male & 66 & 32 & 122 & 99 & 3.0 & 13.6 & 62.1 & 2.3 & 0.280 \\
\hline Control & Female & 74 & 29 & 143 & 60 & 2.8 & 12.5 & 62.1 & 2.2 & 0.300 \\
\hline Control & Female & 74 & 25 & 137 & 64 & 2.7 & 16.0 & 53.1 & 3.1 & 0.280 \\
\hline Control & Female & 82 & 31 & 128 & 82 & 2.8 & 10.1 & 56.9 & 2.8 & 0.265 \\
\hline Control & Female & 85 & 37 & 129 & 78 & 3.0 & 12.1 & 71.7 & 3.1 & 0.290 \\
\hline Control & Female & 89 & 23 & 129 & 81 & 2.4 & 10.5 & 59.5 & 2.9 & 0.265 \\
\hline Control & Male & 91 & 25 & 120 & 71 & 2.7 & 16.0 & 70.1 & 2.3 & 0.220 \\
\hline Control & Female & 83 & 27 & 134 & 65 & 2.6 & 9.0 & 58.2 & 2.5 & 0.290 \\
\hline Control & Female & 87 & 25 & 146 & 94 & 2.5 & 10.1 & 65.0 & 2.2 & 0.270 \\
\hline Control & Male & 61 & 29 & 140 & 80 & 2.5 & 11.4 & 63.3 & 2.4 & 0.240 \\
\hline
\end{tabular}

triglycerides, and class of antihypertensive drugs were tested using regression analysis. None of these clinical characteristics had significant effect on analyzed parameters. Statistica version 9 software was used for statistical analysis. Differences were considered significant if the two-sided $P$ value was 0.05 or less.

\section{Results}

In order to examine glutathione antioxidant defense system in elderly patients treated for hypertension, we analyzed concentration of glutathione (GSH) and activities of the main antioxidant enzymes involved in metabolism of glutathione i.e., glutathione peroxidase (GPx), glutathione transferase (GST), and glutathione reductase (GR).

The glutathione metabolism was considerably changed in elderly hypertensive patients compared with healthy controls. We observed significantly increased level $(P<0.01)$ of GSH glutathione in patients with treated hypertension if compared with healthy individuals. The levels of glutathione expressed by hypertensives and controls were $3.1 \pm 0.29$ and $2.6 \pm 0.25 \mathrm{mmol} / \mathrm{L}$, respectively (Fig. 1; Table 2).

We also investigated a possible association of the change in GSH level with the activity of enzymes, which 


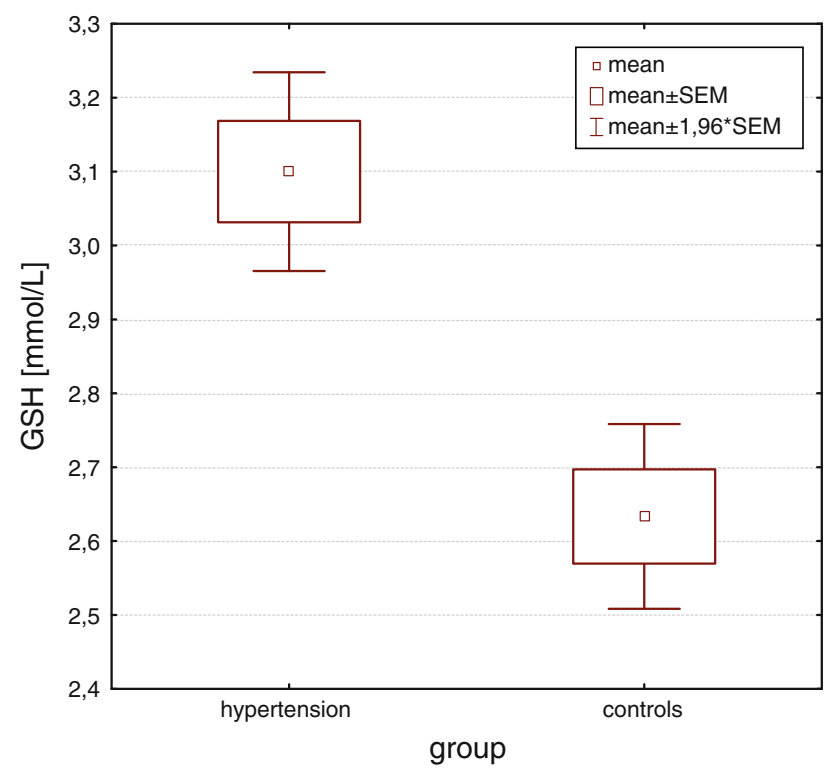

Fig. 1 Mean GSH concentration in hypertensive subjects compared with controls. Independent-samples $t$ test

use GSH as a cofactor for their antioxidant and detoxification capacity. Glutathione peroxidase (GPx), which inactivates peroxides, was unchanged in patients and met the values observed in the controls with the activities of $13.2 \pm 1.95 \mathrm{U} / \mathrm{g} \mathrm{Hb}$ and $13.2 \pm 2.74 \mathrm{U} / \mathrm{g} \mathrm{Hb}$, respectively (Fig. 2; Table 2). We also looked at correlation between GPx activity and GSH concentration. Although no significant interconnections were revealed, the controls exhibited medium negative association (Pearson product-moment

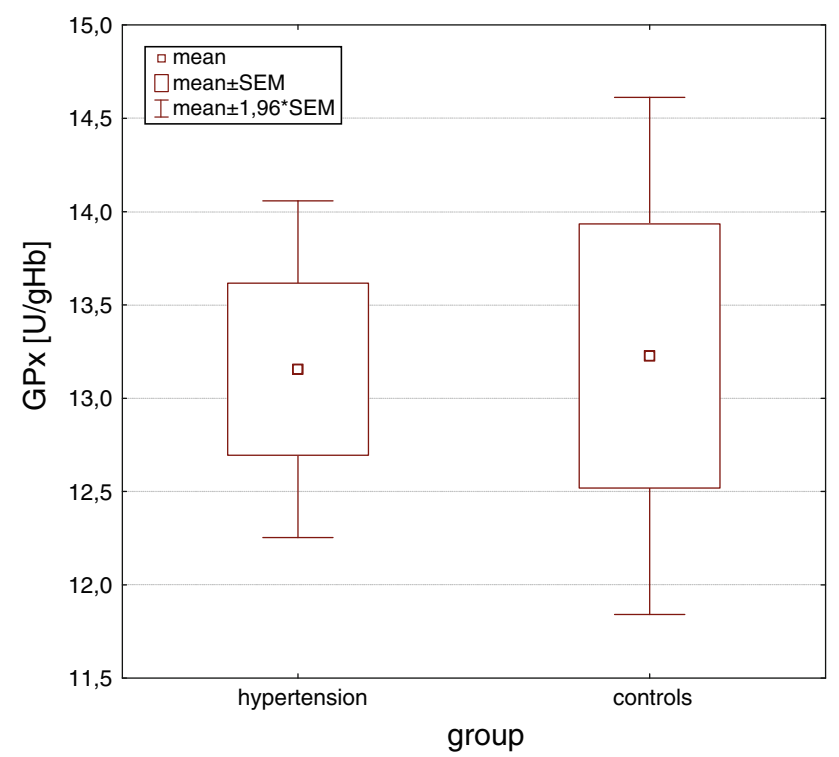

Fig. 2 Mean GPx activity in hypertensive subjects compared with controls. Independent-samples $t$ test correlation coefficient $r=-0.47)$. When Pearson productmoment correlation coefficient between GPx and GSH was determined for the hypertension group, we received value of $r=-0.04$ indicating no association at all.

Unlike GPx, GST activity significantly differed between groups $(P<0.05)$ and was higher in hypertensives than in controls: $3.0 \pm 0.60 \mathrm{mmol} \mathrm{CDNB}-\mathrm{GSH} / \mathrm{mgHb} / \mathrm{min}$ and $2.6 \pm 0.36 \mathrm{mmol} \mathrm{CDNB}-\mathrm{GSH} / \mathrm{mgHb} / \mathrm{min}$, respectively (Fig. 3; Table 2). Regarding correlation between GST activity and GSH level, again no significant association was detected.

Finally, we addressed the question whether the alterations observed in glutathione concentration were related to the change in GR activity. We assumed that elevated level of glutathione is the result of increased activity of GR. Indeed, activity of GR was significantly higher $(P<0.001)$ in patients treated for hypertension than in age- and sexmatched controls with the values of $83.4 \pm 15.25 \mathrm{U} / \mathrm{g} \mathrm{Hb}$ and $64.2 \pm 8.26 \mathrm{U} / \mathrm{g} \mathrm{Hb}$, respectively (Fig. 4; Table 2). However, hypertension group displayed higher activity of the enzyme and consequently higher concentration of $\mathrm{GSH}$, these parameters were not significantly correlated in our study. Interestingly, when looked at the correlation between GR activity and GSH concentration in each group separately, we observed there was a slightly positive correlation between these two parameters in the healthy control population (Pearson product-moment correlation coefficient $r=0.28$ ). When Pearson product-moment correlation coefficient between GR and GSH was determined for the hypertension group, we received value of $r=-0.02$ indicating lack of any interrelation between these parameters.

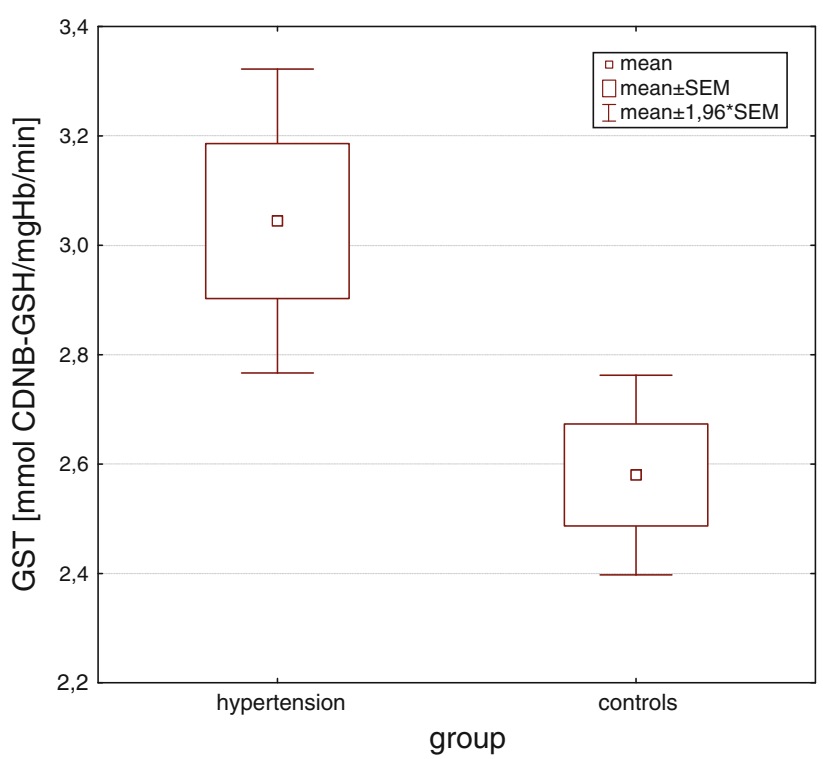

Fig. 3 Mean GST activity in hypertensive subjects compared with controls. Independent-samples $t$ test 


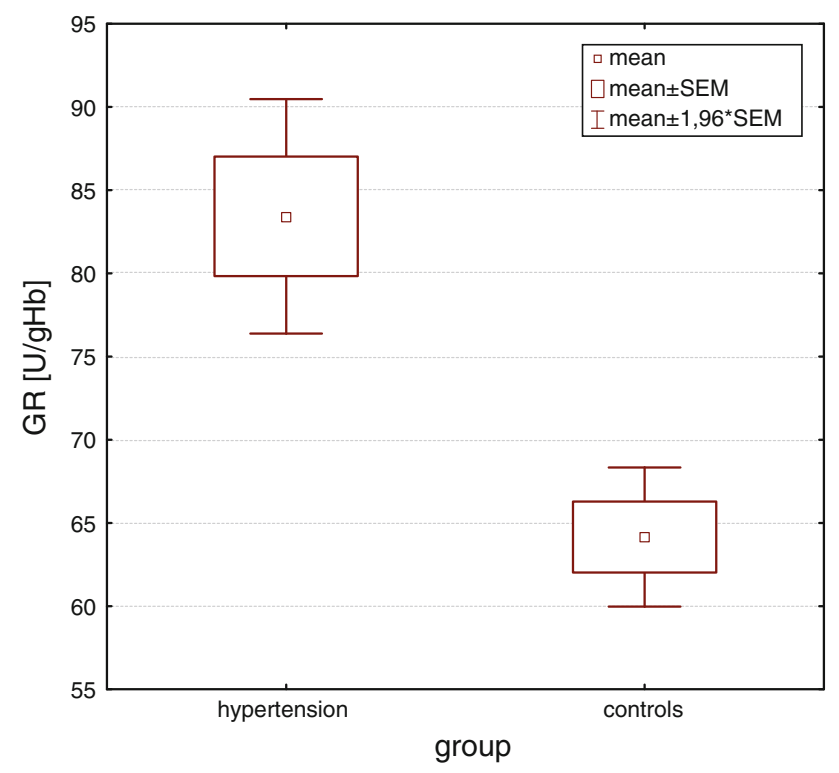

Fig. 4 Mean GR activity in hypertensive subjects compared with controls. Independent-samples $t$ test

\section{Discussion}

Our results suggest disturbances in glutathione-related antioxidant defense system in elderly hypertensive patients since we have observed changes in glutathione concentration and in the activity of glutathione transferase (GST) and glutathione reductase (GR). However, concentration of glutathione and activities of GST and GR were significantly higher in elderly patients treated for hypertension, and GPx-1 had the same activity in hypertensives and controls. Further evidence for the association between glutathione system malfunctions and hypertension was absolute lack of correlations between glutathione concentration and activity of its enzymes in hypertension group. Positive association between GSH and GR and negative association between GSH and GPx were observed only in controls. Since GPx-1 utilizes GSH for the action against peroxides, increased activity of the enzyme caused decrease in GSH concentration. GR is the enzyme that restores GSH from oxidized disulfide GSSG form and that explains why increase in the enzyme activity positively corresponded with GSH level.

The data from our research suggest significantly increased level of glutathione (GSH) in treated hypertensive elderly subjects when compared with non-hypertensive group at similar age. Significantly increased concentration of antioxidant glutathione in patients who were successfully treated for hypertension implies that antihypertensive treatment improved antioxidant defense. In fact, antihypertensive drugs are proven to have antioxidant properties and the ability to lower oxidative stress [7, 9, 22, 36, 37]. On the other hand, we cannot assume that increased level of glutathione is tantamount to decreased oxidative stress, since high level of GSH can be also seen as an adaptive mechanism to oxidative stress, as the latter induces the endogenous antioxidant such as GSH. Furthermore, the GSH can be also accumulated in erythrocytes when it is poorly utilized by the cells.

Accumulation of GSH in patients could be due to the reduction in the activity of GPx and concomitant increase in GR activity, since both were observed herein. But why GPx activity did not follow the trend of the other enzymes, which significantly increased in activity in hypertensives? Curiously, it has been shown that GPx can be inactivated in the conditions of oxidative stress as superoxide radical $\left(\mathrm{O}_{2}^{--}\right)$can inhibits peroxide function of the enzyme [38]. It could be a case especially that $\mathrm{O}_{2}^{--}$is believed to play major role in hypertension pathology. But on the other hand, we should expect decreased level of superoxide throughout antihypertensive treatment. It should also be taken into consideration that, however, protective role of GPx in coping with oxidative injury and cell death mediated by reactive oxygen species in vivo has been supported by substantial body of evidence, the ability to potentiate reactive nitrogen species (RNS), has been also reported. GPx seems to play contradictory roles in coping with ROS versus RNS [39]. No alterations in GPx activity in hypertensive subjects observed in our study could be a one of the actions to prevent nitrate stress and to maintain lower blood pressure.

One of the mechanisms that links antioxidant and antihypertensive properties can be decreased level of superoxide radical $\mathrm{O}_{2}^{--}$under antihypertensive treatment. This effect can be mediated by increased level of glutathione which is known to prevent PDGF-mediated production of reactive oxygen species by NADH/NADPH oxidase, which is considered to be the main source of vascular ROS and $\mathrm{O}_{2}^{--}$in particular $[6,9,11,22,40]$. Moreover, GSH in reaction with peroxynitrite $\mathrm{ONOO}^{-}$forms $S$-nitrosothiols, which have the ability to inhibit NADPH oxidase [41]. Furthermore, $S$-nitrosothiols subsequently release $\mathrm{NO}$ over prolonged time, thus extend the half-life of NO many-fold and in consequence relax vascular tissue [42-44].

In order to analyze glutathione antioxidant defense system in elderly patients treated for hypertension, we also measured activities of glutathione peroxidase (GPx), glutathione transferase (GST), and glutathione reductase (GR). Concerning GR activity, it was significantly higher in hypertensive patients than in controls. Altogether our results suggest high turnover and oxidation of GSH. Oxidized form of glutathione (GSSG) is the substrate for GR, which restores glutathione in reduced state $[12,45]$. Nevertheless, in our study, the relation between GSH concentration and GR activity was not as elegant as expected, namely these two parameters were not significantly 
correlated. However, medium positive correlation was seen in controls, hypertensives perfectly showed no correlation. It can suggest hypertension-related disturbances in glutathione system, which went haywire in patients when compared with controls.

Results from our research allow us to some extent answer the question what for GSH was intensively used in hypertensives, since we analyzed activity of enzymes for which GSH serves as a cofactor. Interestingly, we observed no difference between controls and hypertension group in the activity of GPx. With regard to hypertension important functions of GPx are reduction in peroxides that has been reported to inactivate vasodilator NO [46] and decomposition of GSNO [47] that play essential role in vascular homeostasis.

For GSNO decomposition in the context of GPx activity, no arbitrary conclusion can be made since the process is complex and can also involve a few other denitrosylases [4751]. Toward inactivation of peroxides, likewise GPx shares its function with other enzyme i.e., glutathione transferase (GST), which role in cellular protection of the erythrocytes against oxidative damage has been apprised [52]. In our study, we noticed significant increase in the activity of GST in treated hypertensive if compared with controls.

GST catalyzes conjugation of GSH with various electrophiles, physiological metabolites, and xenobiotics. The important role of GST is detoxification of ROS and limitation of oxidative damage to the tissues [12, 53-55]. Hypertension is associated with decreased activity of many antioxidant enzymes including GST [56]. Increased GST activity can result in higher GSH demand for conjugation reactions. Further, conjugation regulates synthesis of GSH by increase in $\gamma$-GCS transcription [12] and that is why we looked for association between these parameters. Still, we would like to emphasize the fact that GST activity and GSH concentration were not correlated in our study, and the efflux of conjugates in erythrocytes from hypertensive subjects was not measured. Therefore, the hypothesis that antihypertensive treatment enhances detoxifying capacity by inducing GSTs and modifying GST genotype should be taken into consideration, but more research is required to elucidate this association.

GST is a family of isoenzymes from several classes (alpha, kappa, mu, omega, pi, theta) located in cytosol, mitochondria, and microsomes. When the enzymatic activity of total GST is determined by CDNB, $\theta$-GST seems to be the highest among GST izoenzymes characterized so far from human tissues. $\theta$-GST has been suggested to be functional in the removal of circulating xenobiotic [57]. $\theta$-GST expression is associated with GSTT1 genotype. GSTT1 has 2 alleles, denoted GSTT1*0 for the non-functional allele and $G S T T{ }^{*} 1$ for the functional allele [58]. GSTT1-positive carriers display higher
GST activity and may be protected against oxidative stress and oxidative DNA damage [59]. The association between GSTT1 and hypertension has been established, although the data are not consistent $[13,54,60]$. GSTM $1 * 0 /$ GSTT $1 * 0$ genotype has been identified as a potential genetic risk factor to predict development of essential hypertension [61, 62].

Altogether results of our research suggest that glutathione antioxidant defense system in elderly patients treated for hypertension is changed as significantly higher GSH concentration and activity of GST as well as GR were observed. Consistently, we provide more evidence that oxidative stress plays important role in hypertension pathogenesis. A limitation of this study is the lack of measurement of ROS and/or their by-products, as well as assessment of only selected antioxidants which allows only for speculations and indirect conclusions about oxidative stress. Our results show that glutathione-related antioxidant defense system was enhanced in elderly hypertensive patients treated for their condition. There is important question to be addressed, whether increase in glutathionerelated antioxidant defense system was a result of antioxidant effect of the antihypertensive medication or a compensation mechanism for increased ROS generation due to the disease state. Since we saw decreased level of lipid peroxidation measured as a concentration of malondialdehyde in patients when compared with controls (data not shown), we believe that higher GSH concentration as well as activities of GST and GR was more likely caused by antioxidant properties of the antihypertensives. Alterations in concentration and activity of antioxidants observed during antihypertensive medication could be related to the effect of the treatment on NO bioavailability.

Acknowledgments This study was supported by the grant for $\mathrm{PhD}$ student Joanna Rybka "Stipends for doctorate students-2008/ 2009-ZPORR" financed by European Union from European Social Fund and The Integrated Regional Operational Programme (IROP).

Open Access This article is distributed under the terms of the Creative Commons Attribution Noncommercial License which permits any noncommercial use, distribution, and reproduction in any medium, provided the original author(s) and source are credited.

\section{References}

1. McDonald, M., Hertz, R. P., Unger, A. N., \& Lustik, M. B. (2009). Prevalence, awareness, and management of hypertension, dyslipidemia, and diabetes among United States adults aged 65 and older. Journals of Gerontology. Series A, Biological Sciences and Medical Sciences, 64, 256-263.

2. Escobales, N., \& Crespo, M. J. (2005). Oxidative-nitrosative stress in hypertension. Curr Vasc Pharmacol, 3, 231-246.

3. Dominiczak, A. F., Graham, D., McBride, M. W., Brain, N. J., Lee, W. K., Charchar, F. J., et al. (2005). Corcoran lecture. 
Cardiovascular genomics and oxidative stress. Hypertension, 45, 636-642.

4. Dominguez, L. J., Galioto, A., Pineo, A., Ferlisi, A., Ciaccio, M., Putignano, E., et al. (2010). Age, homocysteine, and oxidative stress: Relation to hypertension and type 2 diabetes mellitus. Journal of the American College of Nutrition, 29, 1-6.

5. Higashi, Y., Noma, K., Yoshizumi, M., \& Kihara, Y. (2009). Endothelial function and oxidative stress in cardiovascular diseases. Circulation Journal, 73, 411-418.

6. Touyz, R. M. (2000). Oxidative stress and vascular damage in hypertension. Current Hypertension Reports, 2, 98-105.

7. Rodrigo, R., Prat, H., Passalacqua, W., Araya, J., Guichard, C., \& Bachler, J. P. (2007). Relationship between oxidative stress and essential hypertension. Hypertension Research, 30, 1159-1167.

8. Ceriello, A. (2008). Possible role of oxidative stress in the pathogenesis of hypertension. Diabetes Care, 31(Suppl 2), S181S184.

9. Grossman, E. (2008). Does increased oxidative stress cause hypertension? Diabetes Care, 31(Suppl 2), S185-S189.

10. Kopf, P. G., Huwe, J. K., \& Walker, M. K. (2008). Hypertension, cardiac hypertrophy, and impaired vascular relaxation induced by 2,3,7,8-tetrachlorodibenzo-p-dioxin are associated with increased superoxide. Cardiovascular Toxicology, 8, 181-193.

11. Csanyi, G., Taylor, W. R., \& Pagano, P. J. (2009). NOX and inflammation in the vascular adventitia. Free Radical Biology and Medicine, 47, 1254-1266.

12. Wu, G., Fang, Y. Z., Yang, S., Lupton, J. R., \& Turner, N. D. (2004). Glutathione metabolism and its implications for health. Journal of Nutrition, 134, 489-492.

13. Bessa, S. S., Ali, E. M., \& Hamdy, S. M. (2009). The role of glutathione $S$-transferase M1 and T1 gene polymorphisms and oxidative stress-related parameters in Egyptian patients with essential hypertension. European Journal of Internal Medicine, 20, 625-630.

14. Redon, J., Oliva, M. R., Tormos, C., Giner, V., Chaves, J., Iradi, A., et al. (2003). Antioxidant activities and oxidative stress byproducts in human hypertension. Hypertension, 41, 1096-1101.

15. Heverly-Coulson, G. S., \& Boyd, R. J. (2010). Reduction of hydrogen peroxide by glutathione peroxidase mimics: Reaction mechanism and energetics. The Journal of Physical Chemistry A, 114, 1996-2000.

16. Dourado, D. F., Fernandes, P. A., Mannervik, B., \& Ramos, M. J. (2008). Glutathione transferase: New model for glutathione activation. Chemistry, 14, 9591-9598.

17. Becker, K., Gui, M., \& Schirmer, R. H. (1995). Inhibition of human glutathione-reductase by $S$-nitrosoglutathione. European Journal of Biochemistry, 234, 472-478.

18. Prasad, A., Andrews, N. P., Padder, F. A., Husain, M., \& Quyyumi, A. A. (1999). Glutathione reverses endothelial dysfunction and improves nitric oxide bioavailability. Journal of the American College of Cardiology, 34, 507-514.

19. Chaves, F. J., Mansego, M. L., Blesa, S., Gonzalez-Albert, V., Jimenez, J., Tormos, M. C., et al. (2007). Inadequate cytoplasmic antioxidant enzymes response contributes to the oxidative stress in human hypertension. American Journal of Hypertension, 20, 62-69.

20. Da Silva, A. P., Marinho, C., Goncalves, M. C., Monteiro, C., Laires, M. J., Falcao, L. M., et al. (2010). Decreased erythrocyte activity of methemoglobin and glutathione reductases may explain age-related high blood pressure. Revista Portuguesa de Cardiologia, 29, 403-412.

21. Apelt, J., Bigl, M., Wunderlich, P., \& Schliebs, R. (2004). Agingrelated increase in oxidative stress correlates with developmental pattern of beta-secretase activity and beta-amyloid plaque formation in transgenic Tg2576 mice with Alzheimer-like pathology. International Journal of Developmental Neuroscience, 22, 475-484.
22. Wassmann, S., Wassmann, K., \& Nickenig, G. (2004). Modulation of oxidant and antioxidant enzyme expression and function in vascular cells. Hypertension, 44, 381-386.

23. Rebrin, I., \& Sohal, R. S. (2008). Pro-oxidant shift in glutathione redox state during aging. Advanced Drug Delivery Reviews, 60, $1545-1552$.

24. Liu, H., Wang, H., Shenvi, S., Hagen, T. M., \& Liu, R. M. (2004). Glutathione metabolism during aging and in Alzheimer disease. Annals of the New York Academy of Sciences, 1019, 346-349.

25. Gil, L., Siems, W., Mazurek, B., Gross, J., Schroeder, P., Voss, P., et al. (2006). Age-associated analysis of oxidative stress parameters in human plasma and erythrocytes. Free Radical Research, 40, 495-505.

26. Hernanz, A., Fernandez-Vivancos, E., Montiel, C., Vazquez, J. J., \& Arnalich, F. (2000). Changes in the intracellular homocysteine and glutathione content associated with aging. Life Science, 67, $1317-1324$.

27. Kasapoglu, M., \& Ozben, T. (2001). Alterations of antioxidant enzymes and oxidative stress markers in aging. Experimental Gerontology, 36, 209-220.

28. Erden-Inal, M., Sunal, E., \& Kanbak, G. (2002). Age-related changes in the glutathione redox system. Cell Biochemistry and Function, 20, 61-66.

29. Goncharova, N. D., Marenin, V. Y., \& Bogatyrenko, T. N. (2008). Stress, aging and reliability of antioxidant enzyme defense. Current aging science, 1, 22-29.

30. Taioli, E., Mari, D., Franceschi, C., Bonafe, M., Monti, D., Bertolini, S., et al. (2001). Polymorphisms of drug-metabolizing enzymes in healthy nonagenarians and centenarians: Difference at GSTT1 locus. Biochemical and Biophysical Research Communications, 280, 1389-1392.

31. Corona, G., Lee, D. M., Forti, G., O’Connor, D. B., Maggi, M., O'Neill, T. W., et al. (2010). Age-related changes in general and sexual health in middle-aged and older men: Results from the European male ageing study (EMAS). The Journal of Sexual Medicine, 7, 1362-1380.

32. Shi, G., Gu, C. C., Kraja, A. T., Arnett, D. K., Myers, R. H., Pankow, J. S., et al. (2009). Genetic effect on blood pressure is modulated by age: The hypertension genetic epidemiology network study. Hypertension, 53, 35-41.

33. Paglia, D. E., \& Valentine, W. N. (1967). Studies on the quantitative and qualitative characterization of erythrocyte glutathione peroxidase. Journal of Laboratory and Clinical Medicine, 70, $158-169$.

34. Habig, W. H., Pabst, M. J., \& Jakoby, W. B. (1974). Glutathione $S$-transferases. The first enzymatic step in mercapturic acid formation. The Journal of biological chemistry, 249, 7130-7139.

35. Flohe, L., \& Gunzler, W. A. (1984). Assays of glutathione peroxidase. Methods in Enzymology, 105, 114-121.

36. Ghiadoni, L., Magagna, A., Versari, D., Kardasz, I., Huang, Y., Taddei, S., et al. (2003). Different effect of antihypertensive drugs on conduit artery endothelial function. Hypertension, 41, 1281-1286.

37. Ward, N. C., Hodgson, J. M., Puddey, I. B., Mori, T. A., Beilin, L. J., \& Croft, K. D. (2004). Oxidative stress in human hypertension: Association with antihypertensive treatment, gender, nutrition, and lifestyle. Free Radical Biology and Medicine, 36, 226-232.

38. Blum, J., \& Fridovich, I. (1985). Inactivation of glutathione peroxidase by superoxide radical. Archives of Biochemistry and Biophysics, 240, 500-508.

39. Lei, X. G., Cheng, W.-H., \& McClung, J. P. (2007). Metabolic regulation and function of glutathione peroxidase-1. Annual Review of Nutrition, 27, 41-61.

40. Sedeek, M., Hebert, R. L., Kennedy, C. R., Burns, K. D., \& Touyz, R. M. (2009). Molecular mechanisms of hypertension: 
Role of Nox family NADPH oxidases. Current Opinion in Nephrology and Hypertension, 18, 122-127.

41. Siems, W. G., Capuozzo, E., Verginelli, D., Salerno, C., Crifo, C., \& Grune, T. (1997). Inhibition of NADPH oxidase-mediated superoxide radical formation in PMA-stimulated human neutrophils by 4-hydroxynonenal-binding to - $\mathrm{SH}$ and - $\mathrm{NH} 2$ groups. Free Radical Research, 27, 353-358.

42. Wu, M., Pritchard, K. A., Jr, Kaminski, P. M., Fayngersh, R. P., Hintze, T. H., \& Wolin, M. S. (1994). Involvement of nitric oxide and nitrosothiols in relaxation of pulmonary arteries to peroxynitrite. American Journal of Physiology, 266, H2108-H2113.

43. Ng, E. S., \& Kubes, P. (2003). The physiology of $S$-nitrosothiols: Carrier molecules for nitric oxide. Canadian Journal of Physiology and Pharmacology, 81, 759-764.

44. Uppu, R. M., Nossaman, B. D., Greco, A. J., Fokin, A., Murthy, S. N., Fonseca, V. A., et al. (2007). Cardiovascular effects of peroxynitrite. Clinical and Experimental Pharmacology and Physiology, 34, 933-937.

45. Murakami, E., Ishii, J., Hiwada, K., \& Kokubu, T. (1988). The role of hypothalamic glutathione in hypertensive animals. Clinical and Experimental Hypertension, 10(Suppl 1), 347-352.

46. Freedman, J. E., Frei, B., Welch, G. N., \& Loscalzo, J. (1995). Glutathione peroxidase potentiates the inhibition of platelet function by $S$-nitrosothiols. Journal of Clinical Investigation, 96 , 394-400.

47. Hou, Y., Guo, Z., Li, J., \& Wang, P. G. (1996). Seleno compounds and glutathione peroxidase catalyzed decomposition of $S$ nitrosothiols. Biochemical and Biophysical Research Communications, 228, 88-93.

48. Sanghani, P. C., Davis, W. I., Fears, S. L., Green, S. L., Zhai, L., Tang, Y., et al. (2009). Kinetic and cellular characterization of novel inhibitors of $S$-nitrosoglutathione reductase. The Journal of Biological Chemistry, 284, 24354-24362.

49. Nikitovic, D., \& Holmgren, A. (1996). S-nitrosoglutathione is cleaved by the thioredoxin system with liberation of glutathione and redox regulating nitric oxide. The Journal of biological chemistry, 271, 19180-19185.

50. Hogg, N., Singh, R. J., Konorev, E., Joseph, J., \& Kalyanaraman, B. (1997). S-Nitrosoglutathione as a substrate for gamma-glutamyl transpeptidase. Biochemical Journal, 323(Pt 2), 477-481.

51. Jourd'heuil, D., Laroux, F. S., Miles, A. M., Wink, D. A., \& Grisham, M. B. (1999). Effect of superoxide dismutase on the stability of S-nitrosothiols. Archives of Biochemistry and Biophysics, 361, 323-330.

52. Onaran, I., Ozaydin, A., Gultepe, M., \& Sultuybek, G. (1998). Transport of glutathione conjugate in erythrocytes from aged subjects and susceptibility to oxidative stress following inhibition of the glutathione $S$-conjugate pump. Mechanisms of Ageing and Development, 103, 195-207.

53. Rebbeck, T. R., Walker, A. H., Jaffe, J. M., White, D. L., Wein, A. J., \& Malkowicz, S. B. (1999). Glutathione $S$-transferase-mu (GSTM1) and -theta (GSTT1) genotypes in the etiology of prostate cancer. Cancer Epidemiology of Biomarkers, 8, 283-287.

54. Marinho, C. R., Alho, I., Correia, M., Falcao, L. M., BrasNogueira, J., \& Bicho, M. P. (2005). Genetic distribution of GSTT1 in hypertensive Portuguese subjects: Association with total plasma glutathione as a marker for oxidative stress. American Journal of Hypertension, 18, 83a-83a.

55. Tew, K. D., \& Ronai, Z. (1999). GST function in drug and stress response. Drug Resistance Updates, 2, 143-147.

56. Bessa, S. S., Ali, E. M. M., \& Hamdy, S. M. (2009). The role of glutathione $S$ - transferase M1 and T1 gene polymorphisms and oxidative stress-related parameters in Egyptian patients with essential hypertension. European Journal of Internal Medicine, 20, 625-630.

57. Chiang, W. L., Hsieh, Y. S., Yang, S. F., Lu, T. A., \& Chu, S. C. (2007). Differential expression of glutathione-S-transferase isoenzymes in various types of anemia in Taiwan. Clinica Chimica Acta, 375, 110-114.

58. Bruhn, C., Brockmoller, J., Kerb, R., Roots, I., \& Borchert, H. H. (1998). Concordance between enzyme activity and genotype of glutathione $S$-transferase theta (GSTT1). Biochemical Pharmacology, 56, 1189-1193.

59. Cornelis, M. C., El-Sohemy, A., \& Campos, H. (2007). GSTT1 genotype modifies the association between cruciferous vegetable intake and the risk of myocardial infarction. The American journal of clinical nutrition, 86, 752-758.

60. Marinho, C., Alho, I., Arduino, D., Falcao, L. M., Bras-Nogueira, J., \& Bicho, M. (2007). GST M1/T1 and MTHFR polymorphisms as risk factors for hypertension. Biochemical and Biophysical Research Communications, 353, 344-350.

61. Oniki, K., Hori, M., Takata, K., Yokoyama, T., Mihara, S., Marubayashi, T., et al. (2008). Association between glutathione $S$-transferase A1, M1 and T1 polymorphisms and hypertension. Pharmacogenetics and genomics, 18, 275-277.

62. Wang, J., Zou, L., Huang, S., Lu, F., Lang, X., Han, L., et al. (2010). Genetic polymorphisms of glutathione $S$-transferase genes GSTM1, GSTT1 and risk of coronary heart disease. Mutagenesis, 25, 365-369. 